\title{
Simulation of Liquefied Petroleum Gas (LPG) Production from Natural Gas Using Fractionation Towers
}

\section{Khaled M. EIBadawy $1^{\# 1}$, Mohamed A. Teamah $2^{\# 2}$,Ali I. Shehata $3^{\# 3}$, Ahamed A. Hanfy $4^{\# 4}$}

\#1 Department of Mechanical Engineering, College of Engineering and Technology, Arab Academy for Science, Technology, and Maritime Transport, Abu-Quir, Alexandria, Egypt

\#2 Department of Mechanical Engineering, College of Engineering and Technology, Arab Academy for Science, Technology, and Maritime Transport, Abu-Quir, Alexandria, Egypt

\#3 Department of Mechanical Engineering, College of Engineering and Technology, Arab Academy for Science, Technology, and Maritime Transport, Abu-Quir, Alexandria, Egypt

\#4 Department of Mechanical Engineering, College of Engineering and Technology, Arab Academy for Science, Technology, and Maritime Transport, Abu-Quir, Alexandria, Egypt

\section{ABSTRACT}

Liquefied petroleum gas (LPG) is used as a fuel in several applications, it can replace diesel and petrol. (LPG) is also filled in cylinders, and used as cooking fuel for households, this is why the price of (LPG) increased over the last few years. This paper focuses on the design and simulation of (LPG) plant in order to decrease the heat consumption in $(\mathrm{kW})$ by each fractionation tower during fractionation. Simulation consists of four fractionation towers and is done by using Aspen HYSYS software. Results showed that the recommended inlet feed tray is at the middle of the tower, to provide enough space to occur heat transfer between descending liquid from the condenser and ascending vapor from the reboiler. Simulation showed that the $9^{\text {th }}$ trays for feed inlet to depropanizer is the proper location for this study giving optimum results. Also operating the tower at lower pressures is recommended if it will not affect the boiling point of the desired component to be separated, where the lowest heat duties were consumed at lowest reboiler pressures.

Key words:LPG, NG, NGL, Fractionation Towers, Distillation Columns, Simulation, Aspen HYSYS, Inlet Feed Tray, Reboiler, Heat Duty, column internals.

Corresponding Author:(Khaled Mohamed Aly El Badawy)

\section{INTRODUCTION}

Natural gas (NG) supplies share about $23 \%$ of the total word energy. It is considered as one of the safest, cleanest and more efficient energy of all energy sources. It can replace coal and oil because natural gas gives less harmful emissions when burn. The processing of natural gas is easier and less complicated than the processing of crude oil, with equally important before it is used by the end users. [1]

Natural gas liquids (NGLs) is a term applied to those hydrocarbons, ethane $\left(\mathrm{C}_{2}\right)$, propane $\left(\mathrm{C}_{3}\right)$, butane $\left(\mathrm{C}_{4}\right)$, pentane $\left(\mathrm{C}_{5}\right)$, and heavier $\left(\mathrm{C}_{5+}\right)$ which must be illuminated from natural gas streams to consider 
methane (C1) as dry gas, this is because hydrocarbons condense in methane pipe lines forming hydrates. (LPG) term is applied to a mixture of propane $\left(\mathrm{C}_{3} \mathrm{H}_{8}\right)$ and butane $\left(\mathrm{C}_{4} \mathrm{H}_{10}\right)$ which are considered as natural gas liquid (NGL), with a ratio of approximate $60 \%$ propane and $40 \%$ butane by mass. The extraction of liquefied petroleum gas (LPG) from natural gas is done by a process called fractionation or distillation by using fractionation towers. This is done based on the different boiling points of each hydrocarbon in the (NGLs) stream. The name of the fractionator gives an idea on the hydrocarbon which will be extracted. Ethane $\left(\mathrm{C}_{2}\right)$ is extracted using deethanizer tower, propane $\left(\mathrm{C}_{3}\right)$ by using depropanizer tower, butane $\left(\mathrm{C}_{4}\right)$ by using debutanizer tower, finally butane splitter to separate ISO butane (i-C $\left.\mathrm{C}_{4}\right)$ from normal butane $\left(\mathrm{n}-\mathrm{C}_{4}\right)$. [2]

LPG has the same properties of natural gas, it is odorless and colorless, but a substance called mercaptant usually is added to (LPG) to give it a characteristic odor.(LPG) is used as fuel for vehicles instead of diesel and petrol, as it burns cleaner with octane number close to 105. [3]Normal butane (nC4) used as a refrigerant called (R-600), ISO butane (i-C4) used as a refrigerant called (R-600a), while propane used as a refrigerant (R290). Mixture of both forming LPG, used as a refrigerant called (R290a). [4]

Many studies simulate different ways for separating and processing of both (NGL) and (LPG) from natural gas. Housam Binous and Ahmed Bellagi [5] performed a simulation of five cases with different techniques, to separate complex hydrocarbons mixture. The aim of this research is to show the effect of using the computer algebra mathematics, for prediction of the heat duties and butane $\left(\mathrm{C}_{4}\right)$ production. Aspen HYSYS program for simulation is used, and a comparison between the cases is illustrated graphically. Another study is done by Ali I. Shehata, et al [6] for simulating natural gas liquids (NGLs) to obtain the optimum results for (NGL) production, with less power consumption, by using Aspen HYSYS software. The results showed that number of trays for each fractionation tower, has an important role in the separation of ethane $\left(\mathrm{C}_{2}\right)$, propane $\left(\mathrm{C}_{3}\right)$ and butane $\left(\mathrm{C}_{4}\right)$, increasing number of trays from 10 to 40 trays, improved the mole fraction of ethane by $2 \%$, propane by $4.5 \%$ and butane by $21 \%$, also the heat duties for deethanizer column decreased by $1.5 \%, 1.7 \%$ for depropanizer, and $29 \%$ for debutanizer column.

Another study is done by Shuaib A. Khan and James Haliburton [7] whom they performed a process for efficient (LPG) and natural gas liquids (NGLs) recovery, in this process top vapor stream product from deethanizer column is cooled after extraction to liquefaction, and then mixed with the inlet vapor phase from hydrocarbon gaseous feed stream, the contact takes place inside a direct heat exchanger, the resulting vapor is ethane and methane, and the liquid is the NGL. This process is repeated in depropanizer column, by which the top vapor product is mixed with (NGL), recovery for propane is about 98 to 99 mole \%, which means more recovery of (LPG). Eldar Khabibullin, et al [8] performed a new design for existing (LPG) production plant in Norway simulation for predicting results is done using UNISIM software. Different cases are simulated with their product, cost, and percentage of (LPG) recovery. The case using conventional fractionation column, and other case for a system called petlyuk column are the best two alternatives, as a mean of heat integration, and reduction of total cost. Many other studies are done to increase the purity of LPG, NGL and LNG, by studying parameters like reflux ratio, and number of trays inside each tower [9-15]

Ahmed Rafiq, et al [16] simulate a method for natural gas liquid (NGL) recovery from natural gas for (LPG) production, by using fractionation towers. Debutanizer tower is used before depropanizer tower, so that the next separation will be easier in extraction as it will only extract propane $\left(\mathrm{C}_{3}\right)$ as top product and butane $\left(\mathrm{C}_{4}\right)$ as bottom product. Simulation takes place using Aspen HYSYS program, and depropanizer column showed less heat consumption in $(\mathrm{kW})$ than when installing it before debutanizer. Sanda Mihalache and Marian Popescu [17] developed a dynamic simulation program using Aspen HYSYS, to predict the production rate of each hydrocarbon, decrease energy consumption for reboilers, and to predict damages and failures which might occurs experimentally, they investigated that that the best way to decrease errors, is by controlling the parameters affecting 
the distillation columns dynamically, like inlet feed temperatures, working pressures, and set them with change in natural gas composition, using Aspen HYSYS software.

\section{MODEL DESCRIPTION}

Simulation of liquefied petroleum gas (LPG) production has been performed as a present study with the same operating conditions of Eldar Khabibullin, et al [8], the present simulation is shown below in figure (1). Parameters that effects the production of (LPG), as inlet feed tray to each fractionation tower, will be studied.This to enhance the separation process of (LPG), and decrease the heat consumption in $(\mathrm{kW})$ during fractionation.(LPG) is separated in almost pure propane (C3), ISO butane (i-C4), and normal butane (n-C4). The process consists of four fractionation towers; each tower is working with 18 trays. The towers are deethanizer column operating at pressure 26 bars, debutanizer column at 17 bars, depropanizer column at 10 bars, and then butane splitter or also called deisobutanizer column at 7 bars.

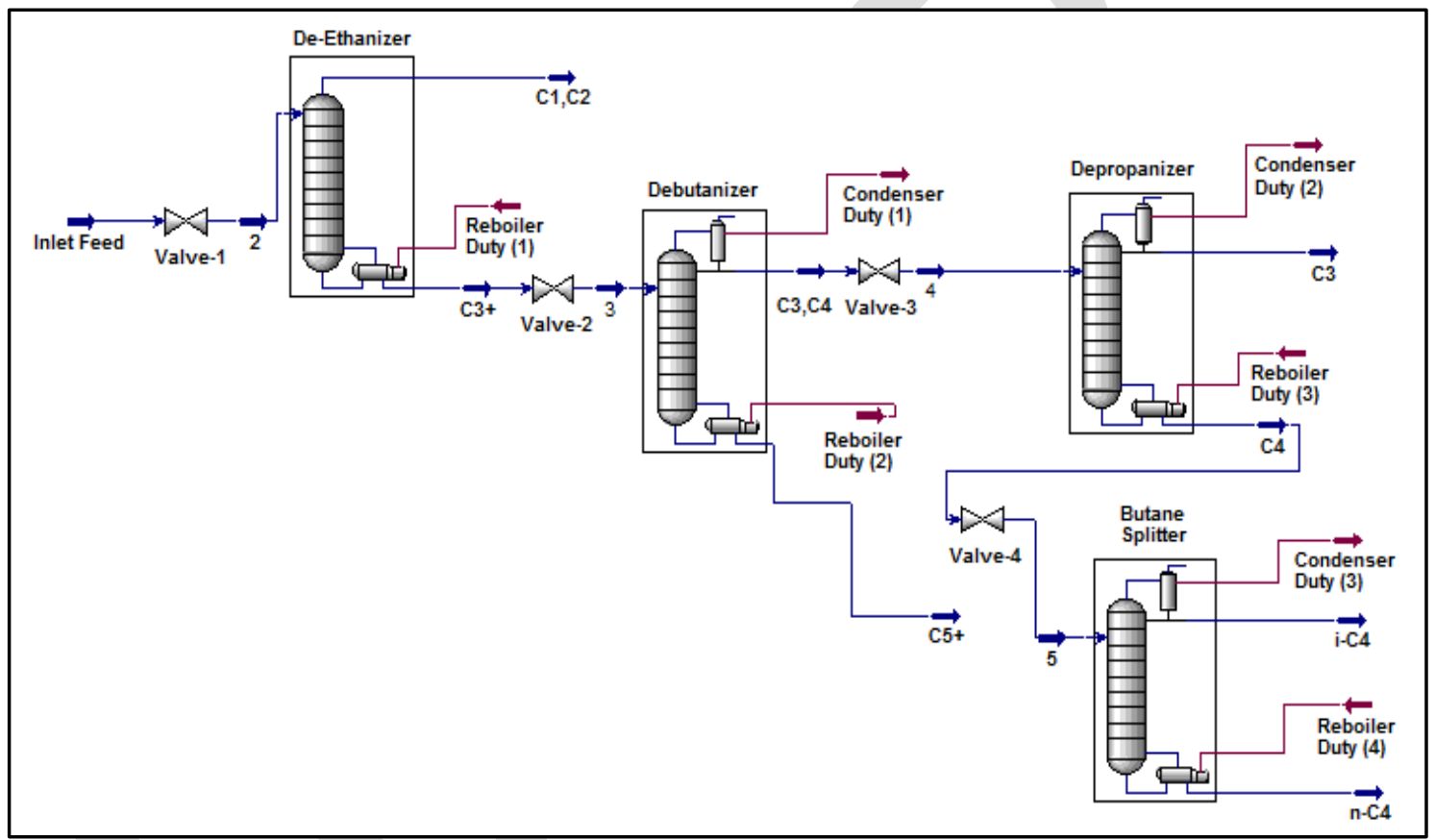

Fig 1: Process flow diagram (PFD) using HYSYS for LPG production from natural gas

Inlet feed composition and feed properties are shown below in table (1)this composition is after applying dehydration and sweetening processes.

The feed enters with pressure of 30 bars, $25{ }^{\circ}$ Ctemperature and flowing with a rate of 33 tones per hour.

Table1. Inlet feed composition to be fractionated with properties

\begin{tabular}{|c|c|}
\hline Property & Inlet Feed \\
\hline Temperature & $25^{\circ} \mathrm{C}$ \\
\hline Pressure & $30 \mathrm{bar}$ \\
\hline Mass flow rate & 33 ton/hr. \\
\hline Composition (mole fraction) \\
\hline $\mathrm{CH}_{4}$ & 0.109 \\
\hline $\mathrm{C}_{2} \mathrm{H}_{6}$ & 0.047 \\
\hline $\mathrm{C}_{3} \mathrm{H}_{8}$ & 0.058 \\
\hline
\end{tabular}




\begin{tabular}{|c|c|}
\hline $\mathrm{i}-\mathrm{C}_{4}$ & 0.031 \\
\hline $\mathrm{n}-\mathrm{C}_{4}$ & 0.058 \\
\hline $\mathrm{i}-\mathrm{C}_{5}$ & 0.053 \\
\hline $\mathrm{n}-\mathrm{C}_{5}$ & 0.048 \\
\hline $\mathrm{n}-\mathrm{C}_{6}$ & 0.084 \\
\hline $\mathrm{C}_{7}$ (Hypothetical) & 0.512 \\
\hline Total composition & 1 \\
\hline
\end{tabular}

\section{MODEL VALIDATION}

As shown in figure (2) and table (2) below,Comparisonis done to the bottom product of deethanizer column, after illuminating methane $(\mathrm{C} 1)$ and ethane $(\mathrm{C} 2)$ from top of the tower. The comparison is for the present and previous study by Eldar Khabibullin, et al [8] for LPG production using Aspen HYSYS software.

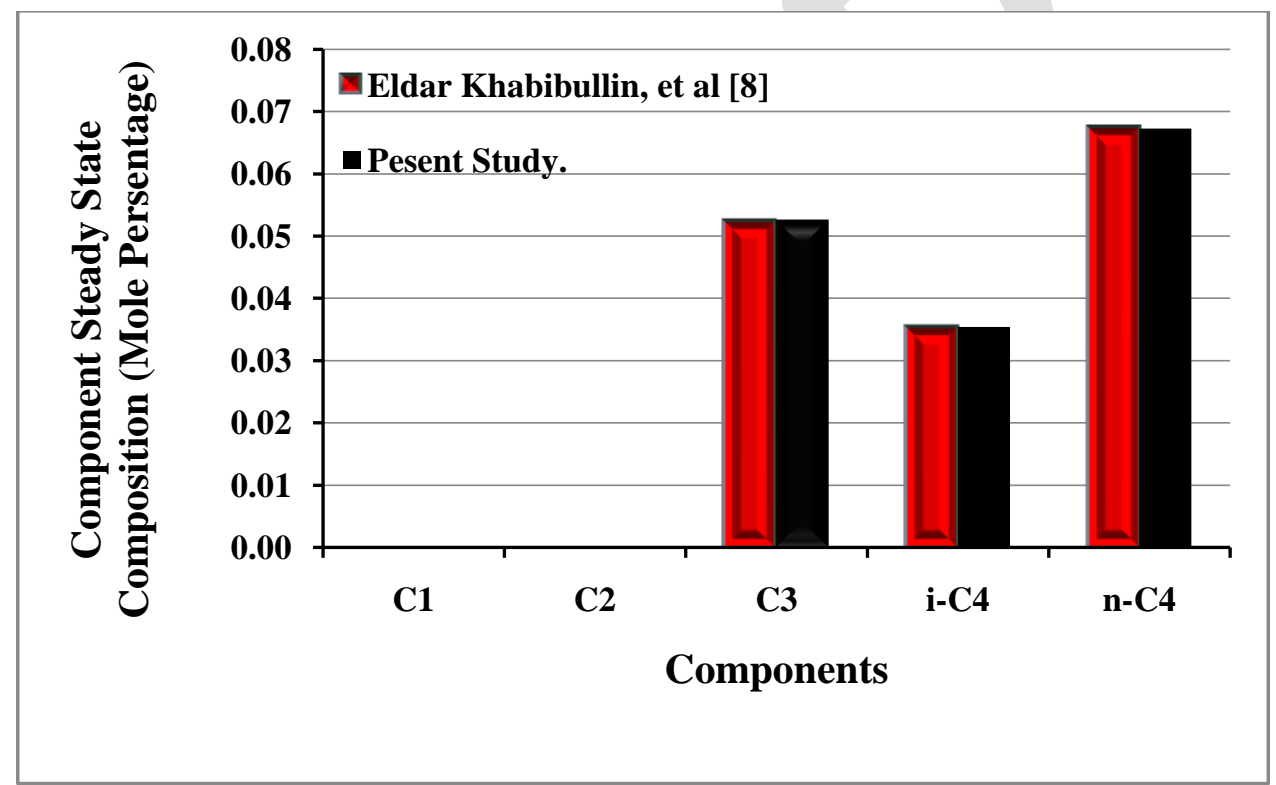

Fig 2: Deethanizer tower bottom product validation for LPG production

Figure (2) illustrates the bottom product composition for methane $\left(\mathrm{C}_{1}\right)$, ethane $\left(\mathrm{C}_{2}\right)$, propane $\left(\mathrm{C}_{3}\right)$, ISO butane (i-C $\left.\mathrm{C}_{4}\right)$, and normal butane $\left(\mathrm{n}-\mathrm{C}_{4}\right)$ as a comparison for the present and previous study. Both methane $\left(C_{1}\right)$ and ethane $\left(C_{2}\right)$ has no values because they are illuminated from top of the tower. Propane (C3) and both products of butane showed high values as it is considered as bottom product for deethanizer tower.

Comparison in figure (2) above between the overhead and bottom products for both studiesshows a good agreement with maximum error of $0.2401 \%$

\section{RESULTS AND DISCUSSIONS}

Figure (3) represents the relation between the inlet feed tray to the tower, and reboiler heat duty for depropanizer tower, at diffent pressures. It has been showed that increasing pressure of the tower will increase the heat duty, as less heat duty is consumed when operating the tower at pressure 8 bar.It is recommended to select the feed tray positionat the middle of the tower, this is to provide enough space to occur heat transfer between descending liquid from the condenser and ascending vapor from the reboiler. So, the lowest heat duty isconsumed at the $9^{\text {th }}$ traywhich located at the middle of the tower when working with any pressure. 


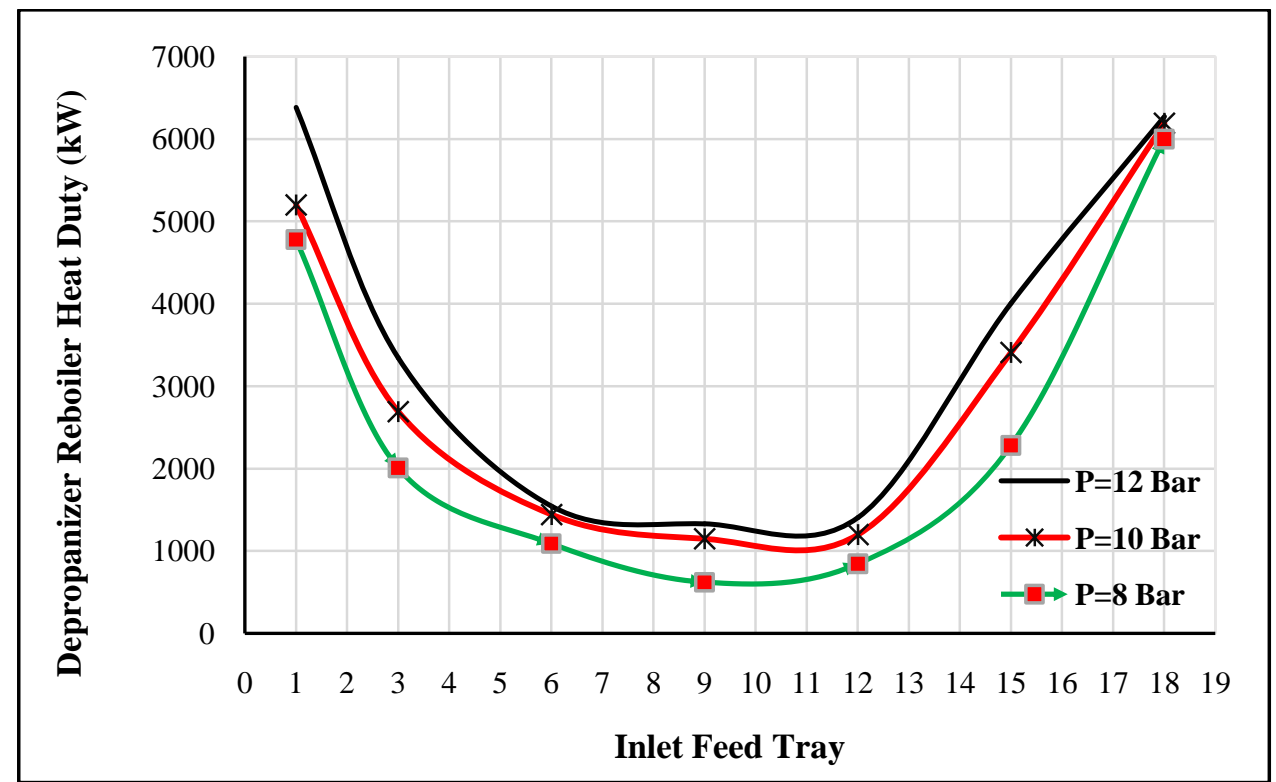

fig 3: Effect of changing feed tray location on Reboiler heat duty for Depropanizer at different pressures.

Table2.Heat duty for depropanizer tower at different pressures and inlet feed tray locations

\begin{tabular}{|c|c|c|c|}
\hline Variable & \multicolumn{3}{|c|}{$\begin{array}{l}\text { Depropanizer Reboiler's Heat Duty (kW) at Different } \\
\text { Pressures. }\end{array}$} \\
\hline $\begin{array}{l}\text { Inlet Feed Tray } \\
\text { Location }\end{array}$ & $P=8$ Bar & $P=10$ Bar & $P=12$ Bar \\
\hline 1 & $4780(\mathrm{~kW})$ & $5200(\mathrm{~kW})$ & $6380(\mathrm{~kW})$ \\
\hline 3 & $2009(\mathrm{~kW})$ & $2690(\mathrm{~kW})$ & $3343(\mathrm{~kW})$ \\
\hline 6 & $1090(\mathrm{~kW})$ & $1441(\mathrm{~kW})$ & $1545(\mathrm{~kW})$ \\
\hline 9 & $620(\mathrm{~kW})$ & $1148(\mathrm{~kW})$ & $1330(\mathrm{~kW})$ \\
\hline 12 & $844(\mathrm{~kW})$ & $1200(\mathrm{~kW})$ & $1406(\mathrm{~kW})$ \\
\hline 15 & $2280(\mathrm{~kW})$ & $3410(\mathrm{~kW})$ & $4004(\mathrm{~kW})$ \\
\hline 18 & 5997(kW) & 6189(kW) & $6270(\mathrm{~kW})$ \\
\hline
\end{tabular}

Table (2) aboveshow that less heat duty is consumed at $9^{\text {th }}$ traywhich located at the middle of the tower, as the tower is operating at 18 trays. Decreasing tower's pressure has significant effect of heat duty. Operating the tower at pressure of 8 bars will decrease the heat duty by $45.9 \%$ from $1148(\mathrm{~kW})$ to $620(\mathrm{~kW})$. It is not recommended to operate the tower at 12 bar, because heat duty will increase by $13.68 \%$ when compared to 10 bars, and by $53.38 \%$ when compared to 8 bars pressure.

\section{CONCLUSION}

This study is a simulation of (LPG)process through different fractionation towers by using AspenHYSY software. Different parameters that enhance the separation process efficiency such as changing operating pressure, and feed tray location were analyzed. Heat Duty consumed by depropanizer tower's reboiler istested to show the impact of changing the inlet feed location on heat duty.

The results showed that selecting the inlet feed at the middle of the tower gives the lowest heat duties for all operating pressures. Less heat duty is consumed at $9^{\text {th }}$ tray. For pressure 10 Bar selecting $6^{\text {th }}$ tray will increase the heat duty from $620(\mathrm{~kW})$ to $1090(\mathrm{~kW})$ by $43.1 \%$, and selecting $12^{\text {th }}$ tray will increase the heat duty from $620(\mathrm{~kW})$ to $844(\mathrm{~kW})$ by $26.54 \%$ which is not recommended. Operating the tower at pressure of 8 bars will decrease the heat duty by $45.9 \%$ from $1148(\mathrm{~kW})$ when operating at 10 bar. to $620(\mathrm{~kW})$. 


\section{REFERENCE}

[1] Economides M, Wang X. Advanced Natural Gas Engineering. Gulf Publishing Company, Houston, Texas, 2009.

[2] Stewart M, Arnold K. Gas sweetening and processing field manual: Gulf Professional Publishing, 2011.

[3] Raslavičius L, Keršys A, Mockus S, Keršienè N, Starevičius M. Liquefied petroleum gas (LPG) as a medium-term option in the transition to sustainable fuels and transport. Renewable and Sustainable Energy Reviews. 2014; 32: 513-25.

[4] Standard A. Energy standard for buildings except low-rise residential buildings. ASHRAE/IESNA Standard. 1999; 90.

[5] Binous H, Bellagi A. Simulation of The Separation of Industrially Important Hydrocarbon Mixtures by Different Distillation Techniques Using Mathematica@. Advances in Systems Engineering Research. 2013: 47-78.

[6] Shehata A.I, Teamah M.A, Hanfy A.A, Ali A.Y. The Simulation of Natural Gas Liquids (NGL) Separation Using Series of Distillation Columns. International journal of advanced science and Technical Research. 2015; 7.

[7] Khan SA, Haliburton J. Process for LPG recovery. United States Patent, 1985.

[8] Khabibullin E, Febrianti F, Sheng J, Bandyopadhyay S, Skogestad S. Process Design and Economic Investigation of LPG production from Natural Gas Liquids (NGL). NTNU Norwegian University of science and Technology. 2010; 41: 99.

[9] Ahmadi A, Dehghani O, Heravi M, Rahimpour M. Performance improvement and efficiency enhancement of a debutanizer column (a case study in South Pars gas field). Journal of Natural Gas Science and Engineering. 2015; 22: 49-61.

[10] Da Silva Linhares LL, De Araújo FMU. Comparitive study of PCA-ANN Hybrid Inferential Systems in Natural Gas Processing units. International Congress of Mechanical Engineering, Natal, RN, Brazil. 2012.

[11] Kirtikumar P, Natubhai, Patel RN. Process for separating and recovering NGLs from hydrocarbon streams. Unitet States Patent, 2015.

[12] Raheem A, Hassan A, Samsudin S, Noor Z, Adebobajo A. Comparative Economic Investigation Options for Liquefied Petroleum Gas Production from Natural Gas Liquids. American Journal of Chemical Engineering Special Issue: Developments in Petroleum Refining and Petrochemical Sector of the Oil and Gas Industry. 2015; 3: 55-69.

[13] Pitman RN, Hudson HM, Wilkinson JD, Cuellar KT. Next generation processes for NGL/LPG recovery. Gas Processors Association, Tulsa, OK (United States), 1998.

[14] Long NVD, Lee M. Improvement of the deethanizing and depropanizing fractionation steps in NGL recovery process using dividing wall column. Journal of Chemical Engineering of Japan. 2012; 45: 285-94.

[15] Long NVD, Kim A, Bakar SHA, Lee M. Improvement of Energy Efficiency in NGL Recovery Process Using Double Prefractionator Arrangement and Double Dividing Wall Column. Theories and Applications of Chemical Engineering. 2011; 17.

[16] Rafiq A, Hladky M, Shadman Far A, Usman M. Fractionation of Natural Gas Liquids to produce LPG. NTNU Norwegian University of science and Technology. 2011.

[17] Mihalache S, Popescu M. Modern Method of Generating the Best Control Structure for Binary Distillation Columns. WSEAS International Conference on SYSTEMS, Agios Nikolaos, Crete Island, Greece. 2007. 